\title{
The Follow-Up of Dietary Treatment of Obesity
}

\author{
Silvio Buscemi* and Salvatore Verga \\ University of Palermo, Dipartimento di Medicina Interna, Malattie Cardiovascolari e Nefro-Urologiche, Policlinico "P. \\ Giaccone". Via del Vespro, 129, I-90127 Palermo, Italy
}

Received: March 31, 2008; Accepted: April 24, 2008; Revised: April 30, 2008

\begin{abstract}
Obesity is a disease with an acknowledged high metabolic and cardiovascular risk, however, only recent studies demonstrated that the dietary treatment of obesity consisting of lifestyle modification programs may be successful in the long run. As for any therapeutic procedure, the dietary hypocaloric treatment of obesity has results and objectives to be verified and surveillance is needed as far as it concerns safety and tolerability. The epidemic of obesity is spreading to impressive levels in the western world; therefore, the treatment of obesity must be cost-effective in order to reach as much people is possible, even for the aspects relative to the follow-up. Unfortunately, there are not significant official guidelines at this regard. In this article, we report the procedures of follow-up as presented in the recent long-term clinical trials that demonstrated the efficacy of the treatment of obesity. Recent patent related to the field are also discussed.
\end{abstract}

Keywords: Obesity, lifestyle intervention, efficacy, tolerability, safety, clinical trials.

\section{INTRODUCTION}

Obesity is an acknowledged risk factor for atherosclerosis and diabetes. The continuous global rise in obesity prevalence has resulted in various dietary weight loss treatments. However, it is necessary that weight reducing strategies achieve as much people is possible and are costeffective, as at the individual as at the general population level. The importance of this issue is increasing in parallel with the expected future growth not only of the dietary treatment options for obesity, but also of the market of antiobesity drugs and of diagnostic laboratory tests. In fact, new options are continuously proposed that claim to be effective in the field of obesity. Recently, Heuer et al. discovered a dietary supplement for supporting weight loss comprising of herbal products [1], Shattuck et al. detected a human gene which seems useful for diagnosing the predisposition to obesity [2], Barak disclosed a method for treating and preventing obesity [3].

Despite the increasing demand of treating obesity, until today no study on the long-term dietary treatment of obesity has specifically addressed the question of which measures are necessary to be monitored during the follow-up in order to evaluate the efficacy as well as the safety and tolerability of the treatment itself. Therefore, in the absence of specific studies, in this paper we approached this matter considering the long term clinical trials that only recently demonstrated the effectiveness of the dietary treatment of obesity in terms of metabolic and cardiovascular risk reduction.

The Diabetes Prevention Program (DPP) [4] provide recent evidence that sustained (the average follow-up was 2.8 years) lifestyle modifications targeting a minimum of $7 \%$ weight loss and 150 minutes of physical activity per week, is able to reduce the incidence of type 2 diabetes by $58 \%$ (metformin intervention reduced the incidence of type 2

*Address correspondence to this author at the Via D. Cimarosa, 5/c, 90145 Palermo, Italy; Tel: 091-6554580; Fax: 091-6552144; E-mail: silbus@ tin.it diabetes by $31 \%$ ). Not surprisingly the cost-effectiveness analysis demonstrated that lifestyle intervention was superior compared with medical therapy among adults in terms of prevention of the onset of new cases of diabetes (metformin intervention resulted not cost-effective after the age of 65 years) $[5,6]$. Participants in the DPP were adult subjects with impaired glucose tolerance; it is not known if lifestyle modification has a favourable cost-effectiveness profile even in normal glucose tolerant otherwise healthy obese people, however, in this case it seems reasonable to assume that a generalized lifestyle intervention is less cost-effective.

Similar to other comorbid conditions that require protracted or chronic treatment, obesity must be considered a clinical entity requiring accurate follow-up including treatment outcome verification, monitoring of treatment progress, and safety. It should be pointed out that many frequent patient follow ups can influence outcomes of obesity therapy given that the number of contacts between the health-care worker and the patient is able to influence independently the degree of weight loss [7]. It is equally important to underscore that in this paper, we will not discuss the follow-up of cases of complicated obesity, expecially if metabolic and/or cardiac complications are involved, because they require a much more articulated approach, neither we deal about the drug treatment of obesity since it concerns each specific drug. Furthermore, efficacy, but safety and tolerability as well, are influenced by the type of dietary treatment itself that may consists of a conventional dietary approach, or semi-fasting, or any special diet. In particular, diets characterized by special macronutrient composition (i.e. the very low-carbohydrate diets) are still lacking of a significant demonstration of long-term efficacy in terms of prevention of the metabolic and the cardiovascular risk. Therefore, in this paper we reviewed only those studies that investigated the effects of conventional diets with long-term follow-up. At the time when this article was written only nine studies (MEDLINE was searched for articles in English published until June 2007) concerned the conventional long term ( $>1$ year) dietary treatment of 
uncomplicated obesity, by alone or in comparison with drug or surgical treatments [4, 8-15].

\section{MEASURES OF DIETARY TREATMENT EFFICACY}

A widely accepted measure of treatment "efficacy" in obese subjects is body weight. Official guidelines as those by the National Institute of Health [16] recommend that body weight is to be measured every four weeks in the first three months of treatment and that a less frequent follow-up is required after the first six months. The frequency with which body weight was obtained during the clinical trials with follow-up longer than one year is quite variable, however a high frequency of body weight measurements has been generally reported. Excluding the SOS study [11] that evaluated surgical treatment, the majority of studies [8-15] measured body weight more frequently in the initial months of treatment (even every one to two weeks) Table 1, with an average frequency of 6.6 times a year (about every two months). The measurement of the body circumferences enters quite rightly among the parameters of evaluation of treatment efficacy. In the clinical studies examined here, body circumferences have usually been measured every 6-12 months. Until recently, there have not been valid reasons to measure regional differences in adiposity (subcutaneous and visceral) by the use of more sophisticated and costly methods. While theoretically, the possibility of monitoring variations in fatty and lean mass during the course of hypocaloric dietary treatment could be interesting, there are no clinical data that prove their utility; furthermore, on the clinical field the most currently-used methods, such as plicometry and bioimpedance, do not seem to guarantee the necessary reliability during the course of weight loss [17, 18]. Almost never, in fact, in the clinical trials reported here, is the evaluation of body composition taken into account to judge the efficacy of the treatment, and, on the other hand, the lean and fatty body compartment sizes are not included in the most recent criteria of classification of obesity.

As previously reported, the main objective of the dietary treatment of uncomplicated obesity is to reduce the risk of diabetes, hypertension and hyperlipidemia that results in lower global cardiovascular risk. In subjects at risk of diabetes, it is certainly important to reduce the incidence of the disease over the long term. In particular, the DPS [12], DPP [4] and Xendos [15] studies have recently evaluated this

Table 1. Indicators of the Result of Dietary Treatment of Obesity and Frequency of Measurements in some Clinical Studies with at Least One Year of Follow-Up

\begin{tabular}{|c|c|c|c|c|c|}
\hline Author, year & Typology & Follow-up & Body weight & Circumferences & Body composition \\
\hline $\begin{array}{c}\text { DPP, } 2002 \\
{[4]}\end{array}$ & $\begin{array}{l}\text { Lifestyle intervention vs. metformin vs. } \\
\text { placebo (IGT obese subjects) }\end{array}$ & 2.8 years & 0 , every 6 months & 0 , every 6 months & - \\
\hline Zavoral, 1998 [8] & $\begin{array}{l}\text { Orlistat vs. placebo } \\
\text { (NGT obese subjects) }\end{array}$ & 1 year & 0,1 year & 0,1 year & 0,1 year \\
\hline Apfelbaum, 1999 [9] & $\begin{array}{l}\text { Sibutramine vs. conventional diet } \\
\text { (NGT obese subjects) }\end{array}$ & 1 year & $\begin{array}{c}0,2 \text { week; } 1,2,3,4,5 \\
6,7,8,9,10,11,12 \\
\text { months }\end{array}$ & $0,6,12$ months & 0 \\
\hline James, $2000[10]$ & $\begin{array}{l}\text { Sibutramine vs. placebo } \\
\text { (NGT obese subjects) }\end{array}$ & 2 years & monthly & 0,24 months & - \\
\hline $\begin{array}{c}\text { Sjöström, } 2000(\mathrm{SOS}) \\
{[11]}\end{array}$ & $\begin{array}{l}\text { Surgical treatment vs. conventional } \\
\text { treatment } \\
\text { (hypertensive obese patients and/or } \\
\text { diabetics) }\end{array}$ & 8 years & yearly & 0 & - \\
\hline $\begin{array}{l}\text { Tuomilehto, } 2001 \\
\quad \text { (DPS) [12] }\end{array}$ & $\begin{array}{l}\text { Lifestyle intervention vs. control } \\
\text { (IGT obese subjects) }\end{array}$ & 3.2 years & $\begin{array}{l}\text { every } 2 \text { months the first } \\
\text { year, then every } 3 \\
\text { months }\end{array}$ & 0 , yearly & - \\
\hline $\begin{array}{c}\text { McNulty, } 2003 \\
{[13]}\end{array}$ & $\begin{array}{l}\text { Sibutramine vs. placebo } \\
\text { (obese diabetics in therapy with } \\
\text { metformin) }\end{array}$ & 1 year & 0 , monthly & $0,6,12$ months & - \\
\hline Foster, 2003 [14] & $\begin{array}{l}\text { Hypoglucidic diet vs. hypolipidic diet } \\
\text { (NGT obese subjects) }\end{array}$ & 1 year & $\begin{array}{c}0,2,4,8,12,16,20,26 \\
34,42,52 \text { weeks }\end{array}$ & - & - \\
\hline $\begin{array}{l}\text { Torgerson, } 2004 \\
\text { (Xendos) [15] }\end{array}$ & $\begin{array}{l}\text { Orlistat vs. placebo } \\
\text { (NGT or IGT obese subjects) }\end{array}$ & 2 years & 0 , every 3 months & $\begin{array}{l}0,3,6 \text { months, then } \\
\text { every } 6 \text { months }\end{array}$ & - \\
\hline
\end{tabular}


end point, demonstrating, with a follow-up period varying from 2 to around 4 years, that lifestyle modifications (in addition or not to pharmacological treatment with biguanides or orlistat) are able to reduce the incidence of diabetes. The clinical trials that we have considered in our analysis Table $\mathbf{2}$ evaluated this end-point by measuring fasting glycaemia and performing the oral glucose tolerance test, including blood insulin concentrations, every 6 (DPP, Xendos) or 12 (DPS) months. Moreover, the glycated haemoglobin has often been determined annually (DPP). About lipid profile, the prevailing tendency of these clinical trials is to evaluate the blood concentrations of total cholesterol, HDL-cholesterol and triglycerides every 6-12 months. Finally, according to the strategy of reducing cardiovascular risk, the blood pressure (BP) need to be reduced especially in subjects with $\mathrm{BP}$ values already in the high-normal range, according to the guidelines concerning the diagnosis and treatment of hypertension [19]. However, the evaluation of blood pressure (BP) values concerns also the safety and tolerability of the dietary treatment itself and, therefore, it should be performed at every clinical control.

\section{EVALUATION OF SAFETY AND TOLERABILITY}

Current weight-loss methods are not without risk. Weight cycling because of repeated dieting has been associated with cardiovascular events and increased mortality in retrospective cohort studies [20] although a meta-analysis failed to corroborate those findings [21]. In general, the clinical trials that we considered in this paper show that the more frequently reported adverse effects in course of dietary hypocaloric treatment of obesity are constipation (30-60\%), headache (40-60\%), halitosis (5-30\%), muscle cramps (5$30 \%$ ), diarrhoea (5-20\%), general weakness $(5-20 \%)$, all events of not great clinical relevance [4, 8-15]. However, not infrequently, other potentially life-risk adverse events as cardiac arrhythmias, kidney or gallstones may occur [22, 23]. Therefore, due to the possibility of undesirable adverse effects (even if usually non life threatening), the conventional dietary treatment of non-complicated obesity is to be considered a medical act. However, the self-made diet approach without any supervised medical counselling is becoming more and more extensive. In many instances, focusing their interest on the cosmetic rather than medical benefits of weight loss, many patients often recur to selfprescribed commercial weight-loss programs. Furthermore, this trend is confirmed and enforced by the increasing popularity gained by some internet sites (one of them is the www.eDiet.com) that freely offer diets and special diets. A recent six months clinical trial [24] comparing a low-carbohydrate, such as Gambelli et al. discussed in WO08000440 [25], vs. a low-fat diet in dislipidemic otherwise healthy subjects provides an example of the importance of medical supervision. Of 120 enrolled subjects only 79 (66\%) completed the study; towards the end of the study one participant who obtained a body weight reduction of about $16 \mathrm{Kg}$ and a concomitant significant amelioration of lipid profile developed chest pain that lead to the diagnosis of coronary heart disease. This possible adverse event occurred therefore in $1.3 \%$ of the participants under study and is

Table 2. Indicators of the Metabolic and Cardiovascular Objective and Frequency of Measurement in some Clinical Studies with at Least One Year of Follow-Up

\begin{tabular}{|c|c|c|c|c|c|c|}
\hline Author, year & Glycemia & Insulinemia & HbA1c & OGTT & Blood lipids & Blood pressure \\
\hline DPP, $2002[4]$ & $\begin{array}{l}0, \text { every } 6 \\
\text { months }\end{array}$ & 0 , every 12 months & $\begin{array}{l}0, \text { every } 12 \\
\text { months }\end{array}$ & $\begin{array}{l}0, \text { every } 12 \\
\text { months }\end{array}$ & 0 , every 12 months & 0 , every 6 months \\
\hline Zavoral, 1998 [8] & 0,1 year & 0,1 year & - & 0,1 year & 0,1 year & 0,1 year \\
\hline Apfelbaum, 2000 [9] & $\begin{array}{l}0,1,6,12 \\
\text { months }\end{array}$ & - & - & - & $0,1,6,12$ months & $\begin{array}{c}0,2 \text { weeks; } 1,2,3,4,5,6,7 \\
8,9,10,11,12 \text { months }\end{array}$ \\
\hline $\begin{array}{c}\text { James, } 2000 \\
{[10]}\end{array}$ & $\begin{array}{l}0,3,6,12,18 \\
24 \text { months }\end{array}$ & $\begin{array}{l}0,3,6,12,18,24 \\
\text { months }\end{array}$ & $\begin{array}{l}0,3,6,12,18 \\
24 \text { months }\end{array}$ & - & $\begin{array}{l}0,3,6,12,18,24 \\
\text { months }\end{array}$ & monthly \\
\hline $\begin{array}{c}\text { Sjöström, } 2000 \text { (SOS) } \\
{[11]}\end{array}$ & $0,2,8$ years & not specified & not specified & not specified & not specified & $0,2,8$ years \\
\hline $\begin{array}{l}\text { Tuomilehto, } \\
2001 \text { (DPS) [12] }\end{array}$ & 0 , yearly & 0 , yearly & - & 0 , yearly & 0 , yearly & 0 , yearly \\
\hline McNulty, 2003 [13] & every 3 months & every 3 months & $\begin{array}{l}\text { every } 3 \\
\text { months }\end{array}$ & $\begin{array}{l}0, \text { every } 3 \\
\text { months }\end{array}$ & every 3 months & monthly \\
\hline $\begin{array}{c}\text { Foster, } \\
2003[14]\end{array}$ & $\begin{array}{c}0,3,6,12 \\
\text { weeks }\end{array}$ & $0,3,6,12$ weeks & & $0,3,6,12$ weeks & $0,3,6,12$ weeks & $\begin{array}{c}0,2,4,8,12,16,20,26,34 \\
42,52 \text { weeks }\end{array}$ \\
\hline $\begin{array}{c}\text { Torgerson, } 2004 \\
\text { (Xendos) [15] }\end{array}$ & $\begin{array}{c}0, \text { every } 6 \\
\text { months }\end{array}$ & 0 , every 6 months & - & $\begin{array}{c}0, \text { every } 6 \\
\text { months }\end{array}$ & 0 , every 6 months & 0 , every 6 months \\
\hline
\end{tabular}


unacceptably high when the percentage of individuals starting a daily self-prescribed diet is considered.

Therefore, follow-up should include the relative evaluation of "safety". The necessity to watch over the safety of treatment is naturally even more important when pharmacological treatment is undertaken. In this regard, the evaluation of body weight modifications is not only a reliable estimate of the efficacy of treatment, but also a measurement of the adherence and safety to the treatment itself. In fact, an excessively rapid weight loss (generally greater than 4-5 kg per month) must be considered undesirable due to the greater loss of lean mass (over $30 \%$ of the weight lost) [26]. The excessive protein and lean mass loss is associated with an increased health risk and also with the re-gaining of weight lost and the relapse of obesity. The lean body mass, in fact, is the more metabolically active body compartment and it is strongly correlated with energy expenditure (expecially the basal metabolic rate); therefore, a not adequate hypocaloric dietary treatment might induce an excessive loss of lean body mass and a consequent more pronounced energy expenditure reduction that is followed by an earlier energy balance restoration [27, 28].

The already mentioned official guidelines of $\mathrm{NIH}$ actually give few indications about the safety and tolerability follow-up measurements relative to the dietary treatment of obesity. So, in the pre-treatment evaluation, an accurate physical examination, medical history collection and routine laboratory evaluation (if this has not been done within the past year) are recommended. Furthermore, blood electrolytes, liver function tests, complete blood count, total cholesterol, HDL-cholesterol, triglycerides and thyroidstimulating hormone or full thyroid function tests are suggested in a preliminary evaluation; finally, a baseline electrocardiogram is recommended. In order to assess any unwanted side effect of diet, these guidelines recommend a visit every 2-4 weeks during the first 3-6 months of treatment (a less frequent follow-up is required after the first 6 months); during each visit it is suggested the measurement of body weight, blood pressure and heart rate in particular.
The reported frequency of measurement of safety indicators in the clinical trials that we have considered in this article [4, 8-15] is summarized in Table 3. Briefly, it is reported that the clinical examination was performed at least every year, the electrocardiogram was obtained before diet starting and it was reiterated yearly in the long run; similarly, routine laboratory exams were obtained before and every 6 months to 1 year after starting the dietary treatment.

As far as the thyroid function is concerned, it is to be observed that secondary obesity due to low or moderate thyroid hypo-function has a really low frequency, if any, of occurrence [29] (high severe cases of hypothyroidism are generally evident and obesity is not the most important and compelling clinical problem under such circumstances). Furthermore, the screening for hypothyroidism is not actually recommended in the adult population [30]. It seems therefore not justified to evaluate thyroid function tests in all subjects who are going to start a reducing body weight hypocaloric diet as the NIH guidelines suggest [16]. Finally, it should not be forgotten to exclude pregnancy and monitor the menstrual cycle in women.

Recently, the bioimpedance (BIA) method has been proposed as an alternative application to the traditional system of measuring body compartments. Particular interest has the possibility of monitoring the variations of the socalled BIA vector that results from body resistance and reactance (Fig. 1) [31]. Briefly, by plotting in the Cartesian axes the values of resistance against reactance it is possible to obtain the BIA vector that is defined by its length (prevalently conditioned by the resistance) and by its direction (the so-called phase angle that is described between the vector and the abscises axis). The BIA vector varies accordingly to the variations of the body water compartments and it allows the semi-quantitative estimate and the monitoring of their changes in response to therapy or to body weight fluctuations as well. In fact, the length of the BIA vector is inversely correlated with total body water while the phase angle (namely the direction of the vector) is directly related to the ratio between the intra- and extra-

Table 3. Safety Indicators and Frequency of Measurement in some Clinical Studies with at Least One Year of Follow-Up

\begin{tabular}{|c|c|c|c|}
\hline Author, year & Examination & Blood exams & ECG \\
\hline \hline DPP, 2002 [4] & 0, yearly & every 6 months & 0,1 year \\
\hline Zavoral, 1998 [8] & 0,1 year & 0,1 year & $0,6,12$ months \\
\hline Apfelbaum, 2000 [9] & $0,6,12$ months & $0,1,6,12$ months & not specified specified \\
\hline James, 2000 [10] & monthly & $0,3,6,12,18,24$ months & - \\
\hline Sjöström, 2000 (SOS) [11] & 0, yearly & not specified & 0 \\
\hline Tuomilehto, 2001 (DPS) [12] & 0, yearly & 0,3 months & - \\
\hline McNulty, 2003 [13] & monthly & 0, & not specified \\
\hline Foster, 2003 [14] & 0, not specified & 0, every 6 months & \\
\hline Torgerson, 2004 (Xendos) [15] & & & n \\
\hline
\end{tabular}



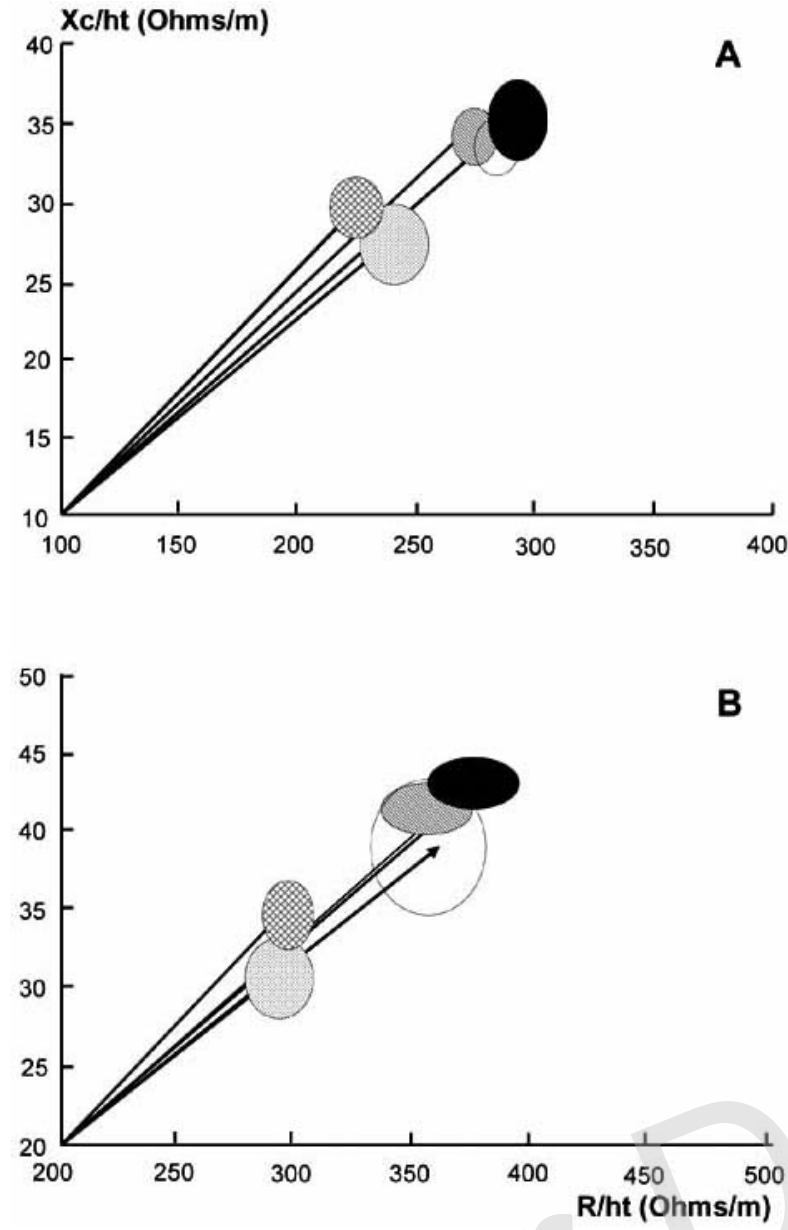

X normal weight NGT subjects; $\triangle \mathrm{Z}$ obese patients NGT;

type 1 diabetics; $\square$ normal weight type 2 diabetics;

$\therefore:$ obese type 2 diabetics.

Fig. (1). Average impedance vector (BIA) and confidence limits 95\% in groups of subjects separated for sex (A men, B women) and pathology; adapted from [31].

cellular body water compartments. The BIA vector is normally distributed inside areas that are sex and body size specific. It is thus possible to estimate through the evolution of the BIA vector, in a semi-quantitative way, if there is an increase or decrease in total body water (the length of the BIA vector respectively decreases or increases) and moreover, if there is an increase or a decrease in the ratio between intra- and extra-cellular water (the phase angle, respectively, increases or decreases). As known, body water compartments reflect health status and intra-cellular water is strictly related with lean body mass. Therefore, informations about the status of body water compartments are of great importance given that they are strongly related with physical well-being. In particular, the BIA vector might alert in the occurrence of a condition of dysnutritional state, even at a subclinical phase. Adequate clinical studies demonstrating the utility of monitoring the BIA vector during the dietary treatment of obesity are not yet available. However, the BIA analysis is a low cost, non invasive, rapid, easy to perform and highly reproducible method; therefore, when the BIA method is available, the analysis of the impedance vector might be carried out at least monthly during the first six months of treatment (namely when the maximum weight loss occurs) as a further criterion for evaluating the efficacy and the tolerability of the dietary treatment.

\section{CURRENT \& FUTURE DEVELOPMENTS}

Specific clinical trials that investigated the safety and tolerability of the dietary treatment of obesity are still lacking. In particular, it needs to be established which measurements and laboratory tests, and with which frequency, should be performed. Near to classical measurements as body weight, waist circumference, blood pressure and some laboratory parameters, other new low cost, reproducible and easy to be performed tests should also be validated. A possible candidate test might be the bioimpedance vector evolution but its possibility of application needs to be confirmed. Future studies should also analyze the costs of the treatment of obesity also for the safety aspects. This is an indispensable basis to allow that the dietary treatment reaches a large amount of the obese population.

\section{ACKNOWLEDGEMENTS}

This article was supported by the Associazione Onlus "Nutrizione e Salute", Italy.

\section{REFERENCES}

[1] Heuer, M., Clement, K., Chaudhuri, S.: WO08028268 (2008)

[2] Shattuck, D. M., Stone, S., Russell, D.L., Abkevich, V., Hunt, S.: US20087314713(2008).

[3] Barak, N.: US20080004324 (2008).

[4] Diabetes Prevention Program Research Group. Reduction in the incidence of type 2 diabetes with lifestyle intervention or metformin. N Engl J Med 2002; 346: 393-403.

[5] Herman WH, Brandle M, Zhang P, et al. Costs associated with the primary prevention of type 2 diabetes mellitus in the diabetes prevention program. Diabetes Care 2003; 26: 36-47.

[6] Herman WH, Hoerger TJ, Brandle M, et al. The cost-effectiveness of lifestyle modification or metformin in preventing type 2 diabetes in adults with impaired glucose tolerance. Ann Intern Med 2005; 142: 323-332.

[7] Wadden TA, Letizia KA. Predictors of attrition and weight loss in patients treated by moderate and severe caloric restriction. In: Wadden TA, VanItallie TB, eds. Treatment of the seriously obese patient. Guilford Press, New York. 1992; 383-410.

[8] Zavoral JH. Treatment with orlistat reduces cardiovascular risk in obese patients. J Hypertens 1998; 16: 2013-2017.

[9] Apfelbaum M, Vague P, Ziegler O, Hanotin C, Thomas F, Leutenegger E. Long-term maintenance of weight loss after a verylow-calorie diet: a randomized blinded trial of the efficacy and tolerability of sibutramine. Am J Med 1999; 106: 179-184.

[10] James WPT, Astrup A, Finer N, et al. (The STORM study group) Effect of sibutramine on weight maintenance after weight loss: a randomised trial. The Lancet 2000; 356: 2119-2125.

[11] Sjostrom CD, Peltonen M, Wedel H, Sjostrom L. Differentiated long-term effects of intentional weight loss on diabetes and hypertension. Hypertension 2000; 36: 20-25.

[12] Tuomilehto J, Lindstrom J, Eriksson JG, et al. (The Finnish Diabetes Prevention Study Group). Prevention of type 2 diabetes mellitus by changes in lifestyle among subjects with impaired glucose tolerance. N Engl J Med 2001; 344: 1343-1350.

[13] McNulty SJ, Ur E, Williams G. (The multicenter sibutramine study group). A randomized trial of Sibutramine in the management of obese type 2 diabetic patients treated with Metformin. Diabetes Care 2003; 26: 125-131. 
[14] Foster GD, Wyatt H, Hill JO, et al. A randomized trial of a lowcarbohydrate diet for obesity. N Engl J Med 2003; 348: 2082-2090.

[15] Torgerson JS, Hauptman J, Boldrin MN, Sjostrom L. Xenical in the prevention of diabetes in obese subjects (XENDOS) study. Diabetes Care 2004; 27: 155-161.

[16] National Institutes of Health. The practical guide. Identification, evaluation, and treatment of overweight and obesity in adults. NIH publication number 00-4084. 2000; 39-40.

[17] Han TS, Carter R, Currall JE, Lean ME. The influence of fat free mass on prediction of densitometric body composition by bioelectrical impedance analysis and by anthropometry. Eur J Clin Nutr 1996; 50: 542-548.

[18] Piers LS, Soares MJ, Frandsen SL, O'Dea K. Indirect estimates of body composition are useful for groups but unreliable in individuals. Int J Obes Relat Metab Disord 2000; 24: 1145-1152.

[19] ESH-ESC. 2003 Guidelines for treatment of hypertension. J Hypertens 2003; 21: 1011-1053.

[20] Lissner L, Odell P, D'Agostino RB, et al. Variability of body weight and health outcomes in the Framingham population. N Engl J Med 1991; 324: 1839-1844.

[21] National Task Force on the Prevention and Treatment of Obesity. Weight cycling. JAMA 1994; 272: 1196-202.

[22] National Task Force on the Prevention and Treatment of Obesity. Very low-calorie diets. JAMA 1993; 270: 967-974.
[23] Everhart JE. Contribution of obesity and weight loss to gallstone disease. Ann Intern Med 1993; 119: 1029-1035.

[24] Yancy WS, Olsen MK, Guyton JR, Bakst RP, Westman E. A lowcarbohydrate, ketogenic diet versus a low-fat diet to treat obesity and hyperlipidemia. Ann Intern Med 2004; 140: 769-777.

[25] Gambelli, L., Schmid, U., Einerhand, A. W.: WO08000440 (2008).

[26] Arguin H, Bouchard DR, Labonté M, et al. Appl Physiol Nutr Metab 2008; 33: 347-355.

[27] Verga S, Buscemi S, Caimi G. Resting energy expenditure and body composition in morbidly obese, obese and control subjects. Acta Diabetol 1994; 31: 47-51.

[28] Froidevaux F, Schutz Y, Christin L. Energy expenditure in obese women before and during weight loss, after refeeding, and in the weight-relapse period. Am J Clin Nutr 1993; 57: 35-42.

[29] Watanakunakorn C, Hodges RE, Evans TC. Mixedema. Arch Intern Med 1965; 116: 183-190.

[30] Helfand M. Screening for subclinical thyroid dysfunction in nonpregnant adults: a summary of the evidence for the US Preventive Services Task Force. Ann Intern Med 2004; 140: 128141.

[31] Buscemi S, Blunda G, Maneri R, Verga S. Bioelectrical characteristics of type 1 and type 2 diabetic subjects with reference to body water compartments. Acta Diabetol 1998; 35: 220-223. 